\title{
Determinantes de la densidad mineral ósea y el papel del ejercicio físico con cargas en personas mayores
}

\author{
Determinants of bone mineral density and the role of loaded \\ exercise in older people \\ Determinantes da densidade mineral óssea e o papel do exercício \\ com cargas em pessoas idosas
}

\begin{abstract}
Giovanny Arenas Sánchez ${ }^{1 *}$, Lorenzo Joaquín Cortés', Matías Arriagada Arce', Luis Peiret Villacura', Alexis Espinoza Salinas ${ }^{1,2}$.
\end{abstract}

Recibido: 16 de marzo de 2021. Aceptado para publicación: 22 de marzo de 2021.

Publicado en línea: 31 de marzo de 2021.

https://doi.org/10.35454/rncm.v4n3.292

\section{Resumen}

Introducción: en los últimos años, las alteraciones que afectan la densidad ósea, como la osteopenia y osteoporosis, se encuentran en aumento. La mejor estrategia para el control de estas enfermedades es el manejo médico-nutricional, donde el ejercicio físico tiene un papel importante; sin embargo, aún existen controversias en la dosificación para el control de la salud ósea.

Objetivos: presentar evidencia actualizada sobre los factores determinantes de la densidad mineral ósea y el rol del ejercicio físico, con cargas sobre la salud ósea en personas mayores.

Métodos: se realizó una búsqueda en PubMed, Cochrane, SciELO, LILACS y ScienceDirect, con las palabras densidad mineral ósea, personas mayores y ejercicio físico. Se procede a abordar, en primer lugar, los cambios fisiológicos del envejecimiento sobre la densidad ósea, luego se analiza el impacto del ejercicio físico con cargas en la salud ósea y los beneficios del ejercicio físico.

Resultados: el ejercicio físico con cargas entre un $50 \%-90 \% 1 \mathrm{RM}$, con un seguimiento de 12 a 26 semanas, realizado 3 veces por semana, con una duración de 30-45 minutos por sesión, contribuye de manera significativa al aumento de la densidad mineral ósea a nivel del cuello femoral y zona lumbar baja en hombres y mujeres mayores. Asimismo, tiene un

\section{Summary}

Introduction: In recent years, disorders affecting bone density such as osteopenia and osteoporosis are on the increase. The best strategy for the control of these diseases is medical-nutritional management where physical exercise plays an important role. However, there are still controversies regarding dosage for the control of bone health.

Objectives: To present updated evidence on the determinants of bone mineral density and the role of physical exercise with loads on bone health in elderly people.

Methods: A search was carried out in PubMed, Cochrane, Scielo, LILACS, ScienceDirect using the words bone mineral density, older people and physical exercise. The physiological changes of aging on bone density are addressed first, followed by the impact of physical exercise with loads on bone health, and the analysis of the benefits of physical exercise.

Results: Physical exercise with weights between $50-90 \% 1 \mathrm{RM}$, with a follow-up of 12 to 26 weeks, performed 3 times a week, with a duration of 30-45 minutes per session, contributes significantly to the increase of bone mineral density at the femoral neck and lower lumbar area in older men and women. It also has a preventive role in cardiovascular diseases and fracture risk.

\section{Resumo}

Introdução: nos últimos anos, têm aumentado as alterações que afetam a densidade óssea, como a osteopenia e a osteoporose. A melhor estratégia para o controle dessas doenças é o manejo médico-nutricional, onde o exercício físico desempenha um papel importante. No entanto, ainda existem controvérsias na dosagem para o controle da saúde óssea.

Objetivos: apresentar evidências atualizadas sobre os determinantes da densidade mineral óssea e o papel do exercício físico com cargas na saúde óssea em idosos.

Métodos: foi realizada uma busca no PubMed, Cochrane, SciELO, LILACS, ScienceDirect com as palavras densidade mineral óssea, idosos e exercício físico. São abordadas primeiro as mudanças fisiológicas do envelhecimento na densidade óssea, depois, se analisam o impacto do exercício físico com cargas na saúde óssea e os benefícios do exercício físico.

Resultados: o exercício físico com cargas entre $50 \%-90 \% 1 \mathrm{RM}$, com seguimento de 12 a 26 semanas, realizado 3 vezes por semana, com duração de 30-45 minutos por sessão, contribui significativamente para o aumento da densidade mineral óssea ao nível do colo femoral e região lombar inferior em homens e mulheres mais velhos. Da mesma forma, tem um papel preventivo nas doenças cardiovasculares e no risco de fraturas. 
papel preventivo de enfermedades cardiovasculares y riesgo de fractura.

Conclusión: el ejercicio físico con cargas a largo plazo tiene efectos benéficos demostrados para la salud ósea, en especial, para disminuir el riesgo de fracturas en personas mayores.

Palabras clave: ejercicio, metabolismo óseo, salud pública, nutrición.
Conclusions: Physical exercise with long-term loads has been shown to have beneficial effects on bone health, especially in reducing the risk of fractures in older people.

Keywords: Exercise; Bone metabolism; Public health; Nutrition.
Conclusões: o exercício físico com cargas a longo prazo tem demonstrado efeitos benéficos na saúde óssea, especialmente na redução do risco de fraturas em idosos.

Palavras-chave: exercício físico, metabolismo ósseo, saúde pública, nutrição.

\footnotetext{
Laboratorio de Fisiología del Ejercicio, Escuela de Kinesiología, Universidad Santo Tomás, Santiago, Chile.

2 Universidad Pablo de Olavide, Sevilla, España.
}

*Correspondencia: Giovanny Arenas Sánchez. garenas2@santotomas.cl

\section{INTRODUCCIÓN}

Con el aumento de la esperanza de vida a nivel mundial se estima que habrá el doble de personas mayores que niños menores de 5 años para el año $2050^{(1)}$. El envejecimiento es un proceso fisiológico, que conlleva una serie de cambios fisiológicos, que van, en algunos casos, al aumento del tejido adiposo $^{(2)}$, resistencia a la insulina ${ }^{(3)}$, pérdida de la masa muscular ${ }^{(4)} y$ densidad ósea ${ }^{(5)}$, con una consiguiente alteración de la capacidad funcional ${ }^{(6)}$. Este declive funcional a nivel óseo se presenta con la pérdida de masa ósea, relacionada con osteopenia y osteoporo$\operatorname{sis}^{(7)}$, siendo esta última la de mayor gravedad e indicador de riesgo de fracturas ${ }^{(8)}$. Destaca que las mujeres inician el proceso de pérdida de masa ósea antes que los hombres, esto sucede por la menopausia ${ }^{(9)}$, en la cual se produce una menor cantidad de estrógenos, lo que impacta de forma negativa en la masa ósea ${ }^{(10)}$.

El tejido óseo es un tejido dinámico, que continuamente está en un proceso de remodelación ${ }^{(11)}$. Este se logra a partir de la interacción entre las células que reabsorben el hueso (los osteoclastos) y las células generadoras de hueso (los osteoblastos) ${ }^{(12)}$. El resultado de este recambio de tejido es la mantención de los huesos sanos y mecánicamente competentes ${ }^{(13)}$. Una alteración del equilibrio entre la actividad de los osteoblastos y de los osteoclastos conduce a una pérdida excesiva de masa ósea (osteoporosis) o a una pérdida parcial de esta (osteopenia) ${ }^{(14)}$.

En la actualidad existen diversos estudios que buscan determinar factores que atenúan este proceso de desmineralización, siendo el ejercicio físico uno de $\operatorname{ellos}^{(15-18)}$. Sin embargo, todavía existen controversias sobre la correcta dosificación del ejercicio físico en la densidad mineral ósea (DMO). El objetivo de este artículo consiste en realizar una revisión bibliográfica actualizada sobre los factores determinantes de densidad mineral ósea y el rol del ejercicio físico con cargas sobre la salud ósea en personas mayores. No se pretende realizar una revisión sistemática ni exhaustiva de la literatura. Para ello se aborda, primero, los cambios fisiológicos por ciertas enfermedades crónicas y por envejecimiento sobre la densidad ósea, luego se analiza el impacto del ejercicio físico con cargas en la salud ósea y, por último, se abordan protocolos de entrenamientos, que tienen efectos positivos en el metabolismo óseo.

\section{MATERIAL Y MÉTODOS}

Se realizó una revisión narrativa de la literatura a través de una búsqueda electrónica en las bases de datos MEDLINE a través de PubMed (www.ncbi.nlm.nih. gov/pubmed), Cochrane Library (www.cochranelibrary.com), SciELO (www.scielo.org), LILACS (lilacs. bvsalud.org) y ScienceDirect (www.sciencedirect. com). La estrategia de búsqueda se construye utilizando los términos Medical Subject Heading Terms ( $\mathrm{MeSH})$ : "bone mineral density" "elderly" "physical exercise" "resistance training" "nutrition" "strength training", "older adults" en forma individual o en conjunto con los operadores booleano "AND" "OR" con la finalidad de obtener resultados concretos y dirigidos a nuestro objetivo (Figura 1).

La búsqueda electrónica se realizó el 12 de octubre de 2020, y estuvo limitada a artículos publicados en inglés y español. Los artículos encontrados por la búsqueda preliminar se analizaron mediante lectura crítica a los resúmenes o texto completo, donde se evaluaron e 


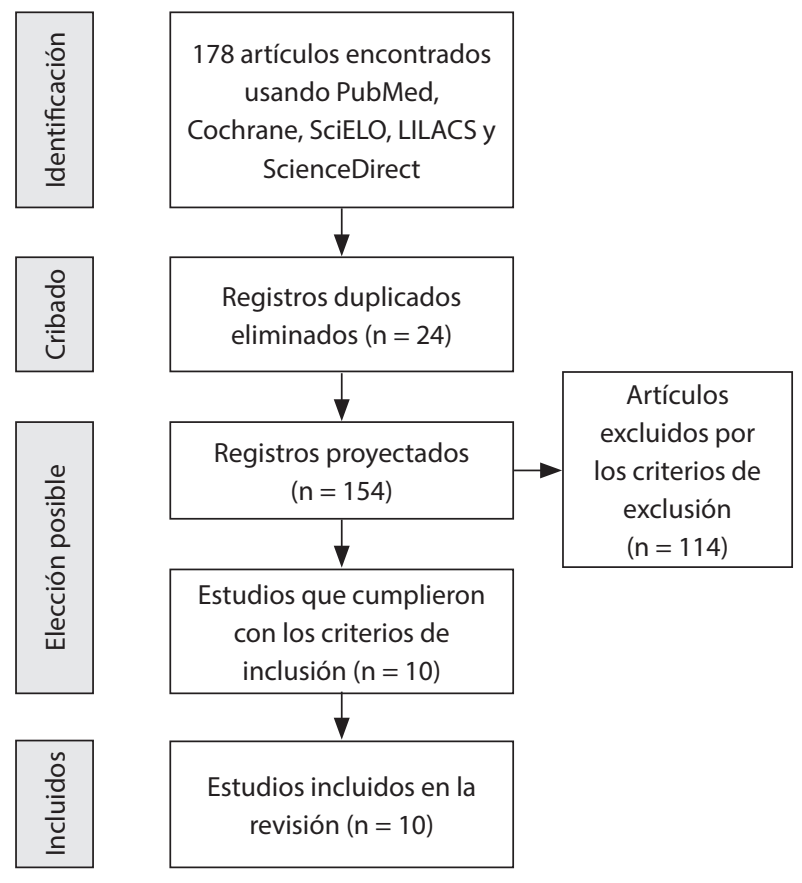

Figura 1. Diagrama de flujo de la estrategia de búsqueda y selección de estudios. Fuente: propia del autor.

incluyeron según los siguientes criterios: artículos originales o revisiones, realizados en humanos de ambos sexos, y que estudian únicamente el efecto de distintos protocolos de ejercicio con cargas y su relación con los mecanismos fisiológicos de respuesta osteogénica y densidad mineral ósea.

Se incluyeron solo estudios clínicos que involucren a participantes hombres y mujeres $\geq 60$ años, en los cuales se intervino solo con ejercicios con carga (ejercicio con pesas, en máquinas y propio peso corporal), que describen la intervención en cuanto a la dosificación. Los resultados se analizan mediante mediciones de densidad mineral ósea, previo y luego del ejercicio. Se excluyeron los artículos que correspondían a editoriales y aquellos realizados en animales. En caso de discrepancias, estas se resolvieron mediante discusión y consenso de los autores, en función de la relevancia y relación de los artículos con el objetivo de estudio de esta revisión.

\section{DESARROLLO}

\section{Factores genéticos y hormonales como determinantes de la masa ósea}

La cantidad de masa ósea es altamente heredable, y se estima que varía entre $60 \%$ a $90 \%{ }^{(19)}$. Dentro del cromosoma genético se determina la ubicación de un gen $^{(20)}$, el cual es llamado loci (locus). Diversos estudios se han encargado de determinar cuáles son los loci que influyen en la $\mathrm{DMO}^{(21-23)}$. También se han identificado variables genéticas que pueden afectar la masa ósea, incluidos los genes relacionados con los osteoblastos, los genes que intervienen en las vías de señalización celular Wnt ${ }^{(24)}$ y en la de osteoprotegerina/receptor activador del ligando del factor nuclear kappa-B (RANKL/ $\mathrm{OPG})^{(25)}$ en los receptores de la vitamina $\mathrm{D}^{(26)}$, en los receptores de estrógenos ${ }^{(27)}$ y proteína 5 relacionada con el receptor de lipoproteínas de baja densidad (LRP5) ${ }^{(28)}$, variaciones en el gen de IL-6 (interleucina 6$)^{(29)}$, de osteocalcina ${ }^{(28)}$, factor de necrosis tumoral alfa $(\mathrm{TNF}-\alpha)^{(30)}$, osteoprotegerina $(\mathrm{OPG})^{(31)}$, factor de crecimiento insulínico tipo $1(\mathrm{IGF}-1)^{(32)} \mathrm{y}$ en el factor de crecimiento transformante beta 1 (TGF- $\left.\beta_{1}\right)^{(33)}$.

Otro factor para la masa ósea son las hormonas, las cuales tienen un rol importante en el proceso de remodelación ósea ${ }^{(34)}$. Las hormonas tiroideas son esenciales para el crecimiento y maduración ósea ${ }^{(35)}$. La síntesis y liberación de las hormonas tiroxina (T4) y triyodotironina (T3) está controlada por el eje hipotálamo-pituitaria-tiroides ${ }^{(36)}$. La hormona T3 estimula la proliferación, diferenciación y síntesis de osteoblastos mediante una regulación positiva de diferentes hormonas, enzimas y receptores, lo que provoca cambios en la mineralización ósea ${ }^{(37)}$. Por otra parte, se induce un aumento en la formación de osteoclastos mediante la vía osteoprotegerina/receptor activador del ligando del factor nuclear kappa-B (OPG/RANKL), que propicia el proceso de resorción ósea (Figura 2$)^{(38)}$.

Otra hormona importante es la hormona de crecimiento (GH), la cual es secretada por la hipófisis como respuesta a la estimulación hipotalámica por la hormona liberadora de crecimiento e inhibición de la somatostatina ${ }^{(39)}$. La GH propicia la formación de osteoblastos, con una ulterior formación ósea ${ }^{(40)}$. Esta participa en la regulación de la parathormona (PTH) y en la hidroxilación de la $1 \propto 25$ hidroxi-vitamina $\mathrm{D}$ en el riñón ${ }^{(41)}$. Además, la GH puede actuar directamente sobre la IGF-1 secretada por el hígado (eje GH-IGF1) ${ }^{(42)}$, y desempeñar una función de osteoblastogénesis y mejorar el proceso de remodelación debido a los depósitos de minerales ${ }^{(43)}$.

Otras hormonas importantes son las llamadas hormonas sexuales (andrógenos y estrógenos). Los andrógenos se sintetizan principalmente en las gónadas masculinas y femeninas, y en menor cantidad en la glándula suprarrenal ${ }^{(44)}$; mientras que los estrógenos se 


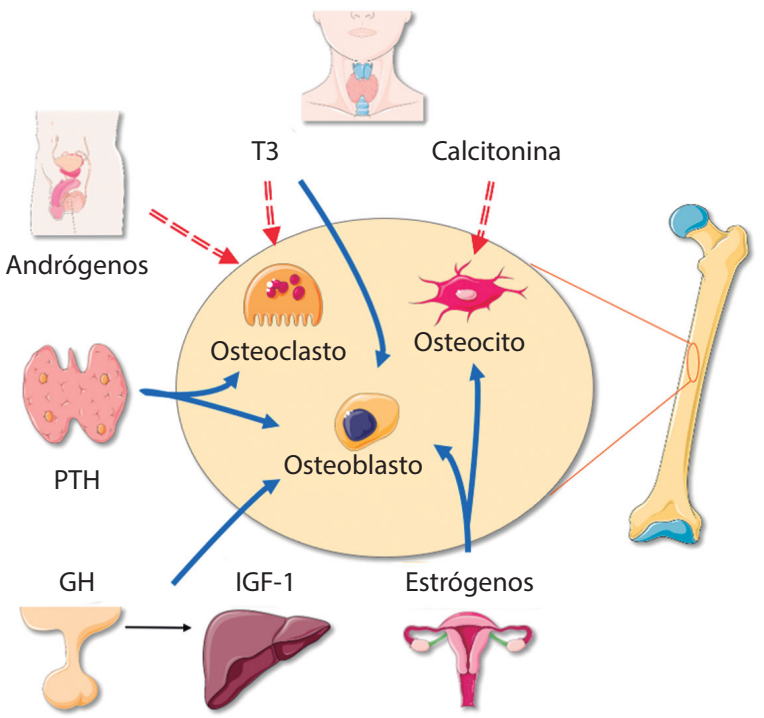

Figura 2. Principales factores hormonales reguladores de la densidad mineral ósea. GH: hormona de crecimiento; IGF-1: factor de crecimiento insulínico tipo 1; PTH: parathormona; T3: triyodotironina. Fuente: propia del autor.

producen por las gónadas femeninas, y en menor cantidad en las masculinas, además por la glándula suprarrenal, tejido adiposo, cerebro, hígado, piel y en los huesos, por el osteoblasto ${ }^{(45)}$. Estas hormonas sexuales tienen una función de evitar la osteoclastogénesis, inhibir el proceso de apoptosis de osteoblastos y osteocitos, y evitar la formación de osteoclastos, lo que regula positivamente la OPG en la vía de señalización celular RANK/OPG (Figura 3) $)^{(46)}$.

La calcitonina es una hormona secretada por las células parafoliculares de la glándula tiroides ${ }^{(48)}$, en respuesta al aumento de calcio sérico ${ }^{(49)}$. Esta hormona actuaría al disminuir la reabsorción de calcio en el riñón ${ }^{(19)}$ y al inhibir la formación ósea a través de la reducción en la liberación de la esfingosina-1-fosfato (SP1) por los osteoclastos ${ }^{(50)}$. También podría intervenir en la síntesis de esclerostina ${ }^{(49)}$.

Finalmente, la PTH es una hormona secretada por las glándulas paratiroideas, en respuesta a la concentración de calcio sérico ${ }^{(51)}$. Tiene como primer órgano diana el riñón, y de forma secundaria actúa en el tracto gastrointestinal, en donde el calcio se reabsorbe, siendo el principal órgano el tejido óseo ${ }^{(52)}$. Es en el tejido óseo donde se promueve la diferenciación y la actividad de los osteoblastos con la producción de nueva matriz ósea, lo que mineraliza el tejido óseo e inhibe la producción de esclerostina por los osteocitos ${ }^{(53)}$; sin embargo, también tiene una función de osteoclastogénesis ${ }^{(46)}$. Según su regulación, esta hormona favorece o no la reabsorción ósea ${ }^{(53)}$.

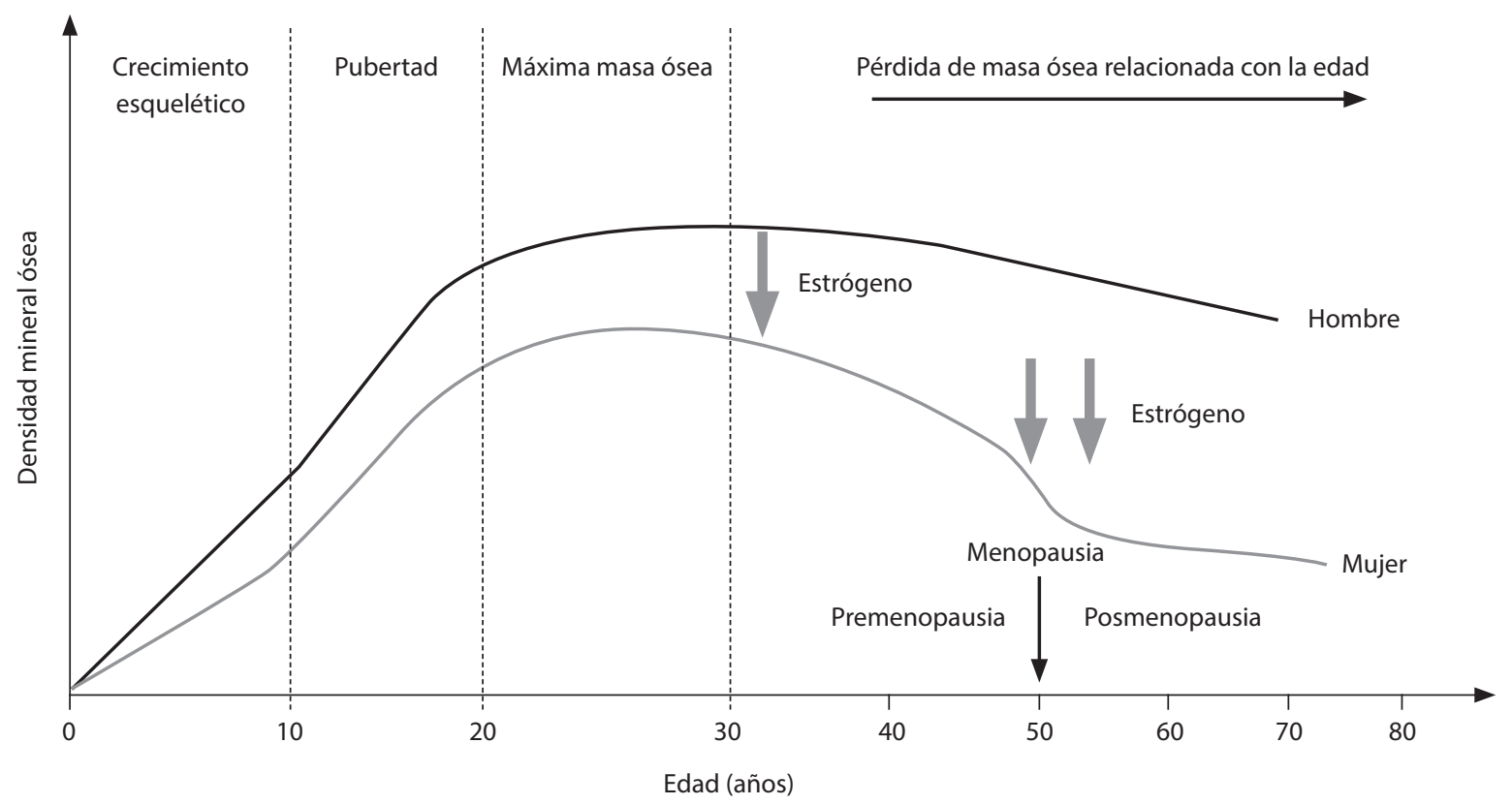

Figura 3. Cambios de la densidad mineral ósea a lo largo del ciclo de la vida por género, y la disminución en la síntesis de estrógeno en las mujeres. Tomada de ${ }^{(47)}$. 


\section{Asociación entre la nutrición y la densidad de masa ósea}

La nutrición es un factor determinante de la salud ósea $^{(54)}$. En general, nos podemos encontrar con dos tipos de patrones dietéticos: los saludables, que se caracterizan por un alto consumo de frutas y verduras, cereales integrales, frutos secos y legumbres, productos lácteos bajos en grasa, aves y pescado ${ }^{(55)}$. Estos productos son la base de las dietas mediterránea y oriental ${ }^{(56)}$, además, son ricos en calcio y vitamina $\mathrm{D}^{(55)}$. La vitamina $\mathrm{D}$ es una hormona esteroide, que participa en el metabolismo del calcio y la homeostasis ósea ${ }^{(57)}$, la cual se va a sintetizar en el hígado, convirtiéndose en 25-hidroxivitamina $\mathrm{D}$, para luego ser transportada al riñón, donde se convierte en 1,25-dihidroxicolecalciferol $(1,25$ $(\mathrm{OH}) 2 \mathrm{D})^{(54)}$, siendo su función principal la regulación de la homeostasis del calcio ${ }^{(58)}$. Por consiguiente, una dieta saludable está asociada directamente con la $\mathrm{DMO}$, un menor riesgo de fractura ${ }^{(56)}$ y también se asocia inversamente con biomarcadores de resorción ósea (suero telopéptido C-terminal $[\mathrm{CTX}])^{(59)}$. En cambio, una dieta poco saludable se asocia inversamente con la salud ósea ${ }^{(56)}$, con una prevalencia de DMO baja ${ }^{(60)} y$ con un mayor riesgo de fractura de cadera ${ }^{(61)}$.

\section{Principales enfermedades crónicas que afectan la densidad de la masa ósea}

Según la evidencia, a lo largo del tiempo se le ha otorgado a la obesidad un efecto protector sobre la masa ósea, incluso la pérdida de peso en adulto mayores puede colocar en cierto peligro la densidad ósea y ser 3 veces más un factor de riesgo de fractura ${ }^{(62)}$. Por otra parte, existen estudios/revisiones que ofrecen una visión contraria a esta idea ${ }^{(63)}$, que describen que el tejido adiposo blanco es un tejido dinámico, que puede estar implicado activamente en las reacciones metabólicas a través de la secreción de hormonas (adipoquinas) y factores inflamatorios, los cuales, a su vez, son promotores de la resorción ósea.

Otra revisión ${ }^{(64)}$ complementa a esta última, y describe la acción que generan los adipocitos a través de la leptina sobre la vía endocrina. La leptina tiene una doble función cuando se encuentra circulante, primero actúa directamente sobre las células óseas, con el fin de aumentar la formación ósea, pero cuando actúa a través del hipotálamo, la leptina puede inhibir el proceso de formación óseo a través de una mayor activación del sistema nervioso simpático. Incluso se concluye, desde los últimos años, que una médula ósea infiltrada de grasa es la responsable de la osteoporosis, por una diferenciación desequilibrada del progenitor común hacia los adipocitos, en lugar de los osteoblastos, bajo la influencia de varios factores en un proceso muy complejo, siendo aún no bien comprendido cuáles son estos factores, y si la grasa de la médula ósea es una causa o una consecuencia de la osteoporosis ${ }^{(65)}$.

La diabetes mellitus tipo 2 (DMT2) es otra patología asociada con una mala calidad ósea ${ }^{(66)}$ y con la obe$\operatorname{sidad}^{(67)}$, junto a un mayor riesgo de fracturas ${ }^{(68)}$. De acuerdo con factores específicos de DMT2, como la hiperglucemia, las adipoquinas y los medicamentos antidiabéticos, estos tienen serios efectos en la salud ósea ${ }^{(69)}$. Otros autores sugieren que a partir de las complicaciones microvasculares y los productos finales de glicosilación avanzada (AGE) existe una gran interferencia en el metabolismo óseo de pacientes con DMT2 $2^{(70,71)}$.

Otra patología a nivel musculoesquelética es la sarcopenia, la cual fue acuñada por Rosenberg, en $1987^{(72,}$ ${ }^{73)}$, para referirse a la pérdida de masa muscular asociada con la edad. Con el tiempo, la definición de sarcopenia ha evolucionado, y se ha complementado con la idea de resaltar la fuerza muscular y el rendimiento físico ${ }^{(74)}$, siendo definida como una disminución de la masa y de la fuerza muscular, así como del rendimiento ${ }^{(75)}$.

El mecanismo exacto del desarrollo de la sarcopenia aún no está claro. Datos actuales sugieren que es un proceso multifactorial, y se cree que es el resultado de factores intrínsecos que involucran cambios en los niveles moleculares, celulares y extrínsecos, como la nutrición y el ejercicio ${ }^{(76)}$. Hueso y músculo están interconectados no solo debido a sus superficies adyacentes, sino química y metabólicamente ${ }^{(77)}$. El músculo libera moléculas endocrinas que afectan al hueso, como la GH, IGF-1, OPG, irisina, osteonectina, factor de crecimiento de fibroblastos-2, IL-6, IL-15 y la miostatina ${ }^{(78)}$. La miostatina, miembro de la familia del TGF- $\beta$, tiene como función inhibir el crecimiento del músculo esquelético, pero también posee efectos sobre los huesos y los tendones ${ }^{(79,80)}$. Como consecuencia de esta interacción, la sarcopenia puede contribuir a la evolución de una DMO por su origen multifactorial y por sus vías fisiopatológicas, que comparte en el proceso de síntesis y degradación/reabsorción ${ }^{(81)}$.

La artritis reumatoide (AR), caracterizada por una sinovitis persistente, inflamación sistémica y daño al cartílago articular y hueso, tiene una alta influencia en la salud ósea ${ }^{(79,82)}$. Esta destrucción del tejido óseo se debe, en principio, a una erosión ósea, que conlleva a una pérdida del tejido óseo por el aumento de la actividad de los osteoclastos ${ }^{(83)}$. Los principales desencadenantes de 
la erosión ósea articular son la sinovitis, que incluye la producción de citocinas proinflamatorias y del ligando activador del receptor del factor nuclear $\kappa B$ (RANKL), el cual es esencial para el desarrollo, activación y supervivencia de los osteoclastos ${ }^{(83)}$, así como los anticuerpos dirigidos contra las proteínas citrulinadas ${ }^{(84)}$. De esa manera, se considera que la AR es un potente desencadenante de la pérdida ósea, lo que da como resultado osteoporosis y un mayor riesgo de fracturas ${ }^{(85)}$.

\section{Envejecimiento y respuesta osteogénica frente al ejercicio físico con carga}

Todas esas enfermedades crónicas que afectan la calidad ósea se asocian con el envejecimiento, lo cual es un declive fisiológico que ocurre en todos los organismos y a nivel de todos los sistemas ${ }^{(86)}$, caracterizándose por una pérdida de la reserva fisiología en respuesta al estrés ${ }^{(87)}$. Varios son los mecanismos involucrados en el envejecimiento, que pueden explicar este descenso fisiológico, como el daño y la reparación del $\mathrm{ADN}^{(88)}$ (Vijg y colaboradores, 2013), el acortamiento de los telómeros $^{(89)}$, la senescencia celular ${ }^{(90)}$, la pérdida de homeostasis proteica ${ }^{(91)}$, el daño mitocondrial, las especies reactivas de oxígeno (ROS) ${ }^{(92)}$ y la desregulación de las señales celulares ${ }^{(93)}$.

Por otra parte, con el envejecimiento se produce un aumento de osteoblastos, osteocitos apoptóticos ${ }^{(94)} \mathrm{y}$ de osteoclastos $^{(95)}$. Además, se acompaña por un descenso en la formación de osteoblastos, que se produce por la disminución en la diferenciación de las células madre mesenquimales de la médula ósea en osteoblastos, debido a una infiltración de tejido adiposo y, en consecuencia, una menor formación de tejido óseo ${ }^{(95-97)}$. En cuanto a la pérdida de osteocitos, esto provocaría una menor osteogénesis en respuesta a la carga mecánica ${ }^{(95)}$, ya que el osteocito actúa como mecanosensor ${ }^{(98,99)}$, y libera menos esclerostina, la cual tiene una función antagonista a la vía de la señalización Wnt/ $\beta$ catenina (proteínas encargadas en la transducción de señales celulares) ${ }^{(100)}$.

Ante esta condición del envejecimiento, vinculado con la disminución ósea dada por el bajo nivel de ejercicio físico, que estimula el desarrollo de osteopenia y osteoporosis, varios son las propuestas para su disminución y control en personas mayores, siendo el ejercicio físico el más avalado por la evidencia científica ${ }^{(101,102)}$. Aunque el mecanismo subyacente a los efectos del ejercicio sobre la remodelación ósea aún no se comprende completamente, algunas hipótesis parecen más probables.
A nivel fisiológico se comprende que los componentes del ejercicio físico, como la duración, el tipo y la intensidad, son factores que pueden determinar una recuperación, regeneración y adaptación ósea ${ }^{(103)}$, de acuerdo con varios mecanismos, por medio de la activación de una cascada inflamatoria, que involucra células de la inmunidad innata y adaptativa, y mediadores de la inflamación; esto debido a un desencadenamiento de la respuesta inmunológica por el aumento de IL-6 por el músculo esquelético; y, por último, la estimulación de la vía de señalización Wnt, la cual estimula las hormonas paratiroideas y la señalización de las proteínas morfogenéticas ${ }^{(104)}$.

A nivel muscular, el efecto piezoeléctrico es de suma importancia, pues cuando el impulso mecánico transmitido al hueso es convertido por cristales de hidroxiapatita en un impulso eléctrico, se conduce a una mayor mineralización ósea. Otro es el efecto vascular, cuando el aumento de la actividad muscular conduce a una variación positiva en el flujo sanguíneo óseo, lo que mejora el metabolismo local ${ }^{(105)}$. En particular, el ejercicio realizado en condiciones de soporte de peso determina los beneficios más significativos, ya que el estrés mecánico es más intenso ${ }^{(106,107)}$. Además, en una revisión de 789 participantes se identificó que la respuesta ósea al ejercicio es efectiva, siendo medida en la espina lumbar, la cabeza del fémur y en la cadera, zonas donde se ejerce mayor estrés mecánico ${ }^{(108)}$.

Por tanto, es necesario definir bien la dosis de ejercicio física para crear esos cambios fisiológicos. Varios tipos de ejercicios, descritos por la literatura, estimulan el crecimiento y mantenimiento de la masa ósea ${ }^{(108,109)}$, siendo en todo momento fundamental los componentes de la estimulación mecánica por medio de las fuerzas antigravitacionales y el estrés o tensión mecánica a nivel muscular ${ }^{(106,107)}$. El ejercicio aeróbico parece ser particularmente efectivo en la activación enzimática de los osteoblastos, por la capacidad de alcanzar un nivel alto de estrés mecánico, el cual es favorable para la estimulación de la masa ósea ${ }^{(106,107)}$, pero, sobre todo, el ejercicio de fuerza o resistencia, en el cual las articulaciones logran moverse en contra una resistencia en la forma de pesas libres, equipamientos o el mismo cuerpo alcanza todos los beneficios antes menciona$\operatorname{dos}^{(108,110,111)}$.

En las Tablas 1 y 2 se muestran las principales características y resultados de los estudios incluidos, que evalúan los efectos de las intervenciones de EF sobre la densidad mineral ósea en personas mayores. En relación con la frecuencia, se recomienda de 2 a 3 veces a 
Tabla 1. Recomendaciones del ejercicio físico con cargas sobre la densidad mineral ósea en personas mayores

\begin{tabular}{|c|c|c|c|}
\hline Estudio & Tipo de ejercicio & Intensidad y volumen & Frecuencia \\
\hline $\begin{array}{l}\text { Beavers y } \\
\text { colaboradores }^{(114)}\end{array}$ & $\begin{array}{l}\text { Prensa, extensión y flexión de } \\
\text { piernas sentado, pantorrillas } \\
\text { sentado, prensa inclinada, remo } \\
\text { sentado, press de tríceps y curl } \\
\text { de bíceps }\end{array}$ & $\begin{array}{l}\text { - } 70 \% \text { de } 1 \mathrm{RM} \\
\text { - } 3 \text { series } x 10 \text { repeticiones } \\
\text { - } \quad \text { Descanso de } 60 \text { segundos }\end{array}$ & $\begin{array}{l}\text { - } 3 \text { veces por semana } \\
\text { - Duración de } 21 \text { semanas } \\
\text { - Progresión de la carga cuando se } \\
\text { realizan más de } 10 \text { repeticiones en la } \\
\text { tercera serie, en } 2 \text { sesiones consecutivas }\end{array}$ \\
\hline $\begin{array}{l}\text { Cornish y } \\
\text { colaboradores }^{(115)}\end{array}$ & $\begin{array}{l}\text { Press banca, remo sentado, } \\
\text { press de hombro (militar), curl } \\
\text { de bíceps, extensión de tríceps } \\
\text { con mancuerna sobre la cabeza, } \\
\text { prensa de piernas, extensión de } \\
\text { rodilla, estocadas, sentadillas y } \\
\text { flexiones plantares }\end{array}$ & $\begin{array}{l}-60 \%-85 \% \text { de } 1 \text { RM } \\
-\quad 2 \text { a } 4 \text { series } \times 6-12 \\
\quad \text { repeticiones }\end{array}$ & $\begin{array}{l}\text { - } 3 \text { veces por semana } \\
\text { - Duración de } 12 \text { semanas } \\
\text { - Progresión de la carga cada } 3 \text { semanas }\end{array}$ \\
\hline $\begin{array}{l}\text { Cunha y } \\
\text { colaboradores }^{(116)}\end{array}$ & $\begin{array}{l}\text { Press de pecho en máquina, } \\
\text { prensa de pierna horizontal, } \\
\text { remo sentado, extensión de } \\
\text { rodilla, curl de bíceps en banca, } \\
\text { curl de isquiotibiales, extensión } \\
\text { de tríceps en polea y elevación } \\
\text { de pantorrilla sentado }\end{array}$ & $\begin{array}{l}\text { - } 65 \%-75 \% \text { del } 1 \text { RM estimado, } \\
\text { según las repeticiones } \\
\text { máximas objetivo } \\
\text { - } 1 \text { y } 3 \text { series x } 10-15 \\
\text { repeticiones máximas } \\
\text { - Descanso entre series de } 1 \\
\text { a } 2 \text { minutos, y } 2 \text { a } 3 \text { minutos } \\
\text { entre ejercicios }\end{array}$ & $\begin{array}{l}\text { - } 3 \text { veces por semana } \\
\text { - } \text { Duración de } 12 \text { semanas } \\
\text { - } \text { Progresión de la carga en } 2 \% \text { a } 5 \% \\
\text { para los ejercicios de extremidades } \\
\text { superiores, y entre } 5 \% \text { y } 10 \% \text { en } \\
\text { extremidades inferiores, cuando se } \\
\text { realizaron más de } 15 \text { repeticiones }\end{array}$ \\
\hline $\begin{array}{l}\text { Holwerda y } \\
\text { colaboradores }^{(117)}\end{array}$ & $\begin{array}{l}\text { Prensa de piernas, extensión } \\
\text { de rodillas, press de hombro y } \\
\text { prensa de pecho }\end{array}$ & 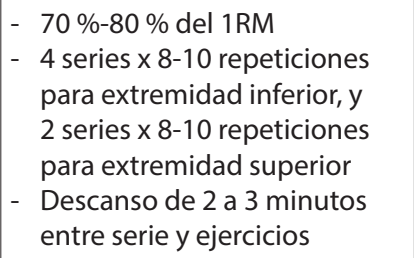 & $\begin{array}{l}\text { - } 3 \text { veces por semana } \\
\text { - Duración de } 12 \text { semanas } \\
\text { - Progresión en la carga cuando se } \\
\text { realizaron más de } 10 \text { repeticiones }\end{array}$ \\
\hline $\begin{array}{l}\text { Huovinen y } \\
\text { colaboradores } \\
(2016)^{(118)}\end{array}$ & $\begin{array}{l}\text { Prensa de piernas, press de } \\
\text { pecho en máquina, remo } \\
\text { sentado, crunch abdominal, } \\
\text { extensiones de espalda, curl } \\
\text { de isquiotibiales sentado y } \\
\text { abducciones de cadera }\end{array}$ & $\begin{array}{l}\text { - } 50 \%-80 \% \text { de } 1 \mathrm{RM} \\
\text { - } 3 \text { series } x \text { 8-15 repeticiones }\end{array}$ & $\begin{array}{l}\text { - } 3 \text { veces por semana } \\
\text { - Duración de } 16 \text { semanas } \\
\text { - Progresión de la carga se ajustó } 1 \text { vez } \\
\text { al mes }\end{array}$ \\
\hline
\end{tabular}

la semana para crear el estrés mecánico suficiente. La intensidad varía entre $50 \%$ a $90 \%$ de $1 \mathrm{RM}$, con una duración por sesión de 30 a 45 minutos $^{(112)}$. Este tipo de ejercicio supone una aplicabilidad segura y con múltiples beneficios en todo rango etario ${ }^{(113)}$.

A partir de las Tablas 1 y 2 se realiza un programa estructurado de ejercicio multicomponente, con una entrada en calor o activación (10 minutos), una fase principal (30-45 minutos) y vuelta a la calma o recuperación (5-10 minutos) (Figura 4).

\section{CONCLUSIÓN}

El ejercicio físico con carga mantiene y mejora la DMO en personas mayores con osteopenia u osteoporosis; pero, para generar un aumento en la DMO se necesitan intensidades específicas (moderada a submáxima y de carácter progresivo), volúmenes (bajo a medio), frecuencias ( 2 a 3 sesiones por semana) y ejercicios específicos, dependiendo de la zona anatómica a mejorar. Además, aunque fueron pocos los estudios que mostraron un efecto positivo, ninguno de los estudios analizados provoca una disminución de la $\mathrm{DMO}$; por lo cual, atribuimos al ejercicio físico con carga un efecto protector sobre el tejido óseo en personas mayores.

\section{PUNTOS CLAVE}

- La osteopenia y la osteoporosis son las enfermedades que más alteran la densidad mineral ósea. 
Tabla 2. Recomendaciones del ejercicio físico con cargas sobre la densidad mineral ósea en personas mayores

\begin{tabular}{|c|c|c|c|}
\hline Estudio & Tipo de ejercicio & Intensidad y volumen & Frecuencia \\
\hline $\begin{array}{l}\text { Kemmler y } \\
\text { colaboradores }^{(18)}\end{array}$ & $\begin{array}{l}\text { Prensa de piernas, extensión de } \\
\text { rodillas, curls de isquiotibiales, } \\
\text { aducción y abducción de cadera, } \\
\text { jalón en polea alta, remo, extensión } \\
\text { de espalda, press de banca y militar, } \\
\text { elevaciones laterales, abdominales, } \\
\text { elevaciones de pantorrillas, } \\
\text { extensión de cadera, pull over y } \\
\text { abdominales laterales }\end{array}$ & 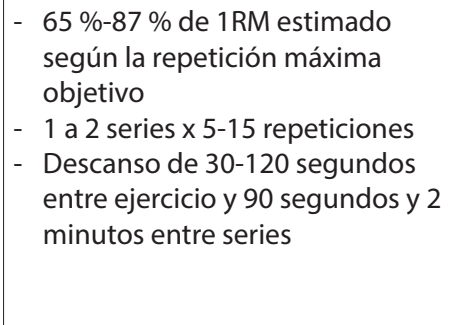 & $\begin{array}{l}\text { - } 3 \text { veces por semana } \\
\text { - Duración } 52 \text { semanas } \\
\text { - Progresión de la carga cada } 8 \text { a } \\
12 \text { semanas }\end{array}$ \\
\hline $\begin{array}{l}\text { Mosti y } \\
\text { colaboradores }^{(119)}\end{array}$ & Sentadilla en máquina & $\begin{array}{l}\text { - } 85 \% \text { a } 90 \% \text { de } 1 \text { RM } \\
\text { - } 4 \text { series } \times 3-5 \text { repeticiones } \\
\text { - } \text { Descanso de } 2 \text { a } 3 \text { minutos }\end{array}$ & $\begin{array}{l}\text { - } 3 \text { veces por semana } \\
\text { - Duración de } 12 \text { semanas } \\
\text { - Sin progresión de la carga }\end{array}$ \\
\hline $\begin{array}{l}\text { Pinto y } \\
\text { colaboradores }^{(120)}\end{array}$ & $\begin{array}{l}\text { Press de banca, elevaciones } \\
\text { laterales, remo sentado, curl de } \\
\text { bíceps, extensión de tríceps, } \\
\text { press de hombros, crunch } \\
\text { de abdominales, aducción y } \\
\text { abducción de cadera, sentadilla, } \\
\text { curl de isquiotibiales, extensión de } \\
\text { cuádriceps, extensiones de columna, } \\
\text { elevaciones de talones, flexiones y } \\
\text { extensiones de tobillo }\end{array}$ & $\begin{array}{l}\text { - } 65 \% \text { de } 1 \text { RM, estimado según las } \\
\text { repeticiones máximas objetivo } \\
\text { - } 3 \text { series x 13-15 repeticiones } \\
\text { máximas, y 10-13 repeticiones } \\
\text { para los crunch de abdominales } \\
\text { - } \text { Descanso de } 60 \text { segundos } \\
\end{array}$ & $\begin{array}{l}\text { - } 3 \text { veces por semana } \\
\text { - Duración de } 12 \text { semanas } \\
\text { - Sin progresión de la carga }\end{array}$ \\
\hline $\begin{array}{l}\text { Shanb y } \\
\text { colaboradores }^{(121)}\end{array}$ & $\begin{array}{l}\text { Ejercicios de peso corporal: } \\
\text { extensión y abducción de cadera, } \\
\text { extensión de rodilla, flexión } \\
\text { de bíceps y tríceps, curl de } \\
\text { isquiotibiales, flexión y extensión de } \\
\text { muñeca, extensión de espalda en } \\
\text { posición bípeda }\end{array}$ & $\begin{array}{l}-25 \% \text { de } 1 \text { RM } \\
-3 \text { series } x 8 \text { repeticiones }\end{array}$ & $\begin{array}{l}\text { - } 2 \text { veces por semana } \\
\text { - Durante } 26 \text { semanas } \\
\text { - Sin progresión de la carga }\end{array}$ \\
\hline $\begin{array}{l}\text { Stunes y } \\
\text { colaboradores }^{(122)}\end{array}$ & $\begin{array}{l}\text { Sentadilla búlgara, press banca, } \\
\text { elevación de pantorrillas, curl de } \\
\text { bíceps con mancuerna, jalón en } \\
\text { polea, press francés, peso muerto } \\
\text { ruso y con pesas, estocadas, remo } \\
\text { sentado en máquina, curl de bíceps } \\
\text { en banco scott, planchas, extensión } \\
\text { de rodillas, prensa de piernas y de } \\
\text { pecho, press de hombro y de banca }\end{array}$ & 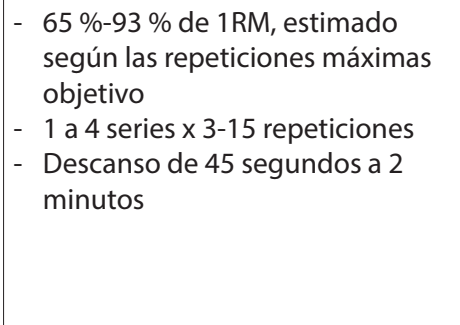 & $\begin{array}{l}\text { - } 2 \text { veces por semana } \\
\text { - Duración de } 12 \text { semanas } \\
\text { - Progresión de la carga semanal }\end{array}$ \\
\hline
\end{tabular}

- Existen factores genéticos y hormonales que influyen en los genes relacionados con los osteoblastos y en el proceso de remodelación ósea.

- La nutrición es un factor determinante de la salud ósea.

- Un bajo nivel de ejercicio físico representa un factor de riesgo importante para la osteoporosis debido a la reducción de la estimulación mecánica de los osteoblastos.

- El ejercicio físico de fuerza genera un estrés mecánico más intenso, el cual puede actuar sobre la estructura ósea, mejorar la función física y disminuir el riesgo de caídas en personas mayores.

\section{Financiamiento}

El presente estudio no tuvo financiación.

\section{Conflicto de intereses}

Los autores declaran no tener conflicto de intereses. 
Calentamiento

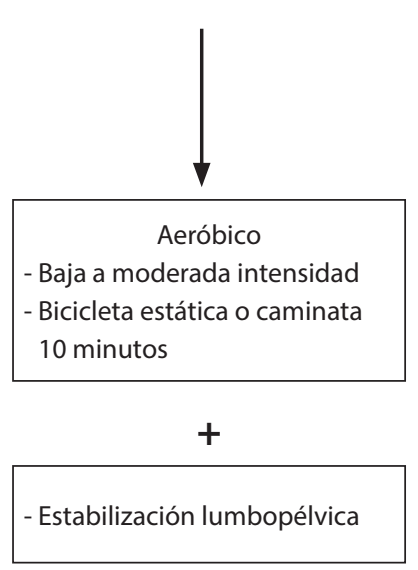

Fase principal o desarrollo

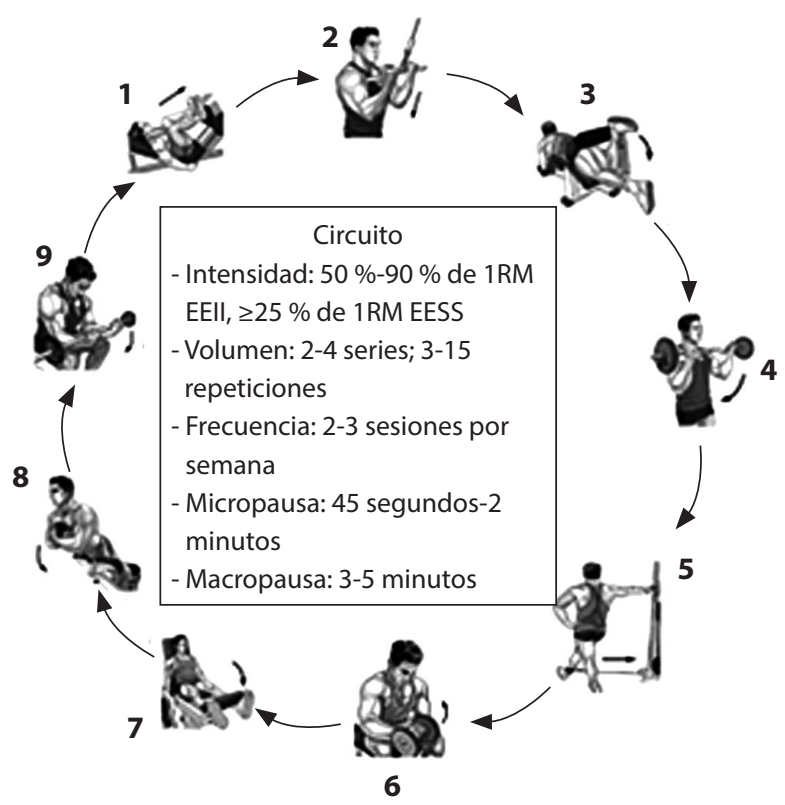

Vuelta a la calma

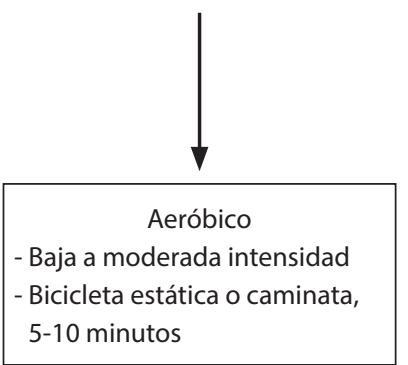

Figura 4. Circuito estructurado de ejercicio físico multicomponente con cargas para mejorar la densidad mineral ósea en personas mayores. EEIl: extremidades inferiores; EESS: extremidades superiores.

\section{Declaración de autoría}

GAS, LC, MA, LPV y AES participaron en la concepción y la redacción. Todos los autores revisaron el manuscrito, acuerdan ser plenamente responsables de garantizar la integridad y precisión del trabajo, y leyeron y aprobaron el manuscrito final.

\section{Referencias bibliográficas}

1. Bales C, Porter Starr K. Obesity interventions for older adults: Diet as a determinant of physical function. Adv Nutr. 2018;9(2):151-9. doi: 10.1093/advances/nmx016.

2. Porter Starr K, Orenduff M, McDonald S, Mulder H, Sloane $\mathrm{R}$, Pieper $\mathrm{C}$, et al. Influence of weight reduction and enhanced protein intake on biomarkers of inflammation in older adults with obesity. J Nutr Gerontol Geriatr. 2019;38(1):33-49. doi: 10.1080/21551197.2018.1564200.

3. Shou J, Chen PJ, Xiao WH. Mechanism of increased risk of insulin resistance in aging skeletal muscle. Diabetol Metab Syndr. 2020;12:14. doi: 10.1186/s13098-020-0523-x.

4. McCormick R, Vasilaki A. Age-related changes in skeletal muscle: Changes to life-style as a therapy. Biogerontology. 2018;19(6):519-36. doi: 10.1007/s10522-018-9775-3.

5. Kim SW, Jung SW, Seo MW, Park HY, Song JK. Effects of bone-specific physical activity on body composition, bone mineral density, and health-related physical fitness in middle- aged women. J Exerc Nutrition Biochem. 2019;23(4):36-42. doi: $10.20463 /$ jenb.2019.0030.

6. Posch M, Schranz A, Lener M, Tecklenburg K, Burtscher M, Ruedl G, et al. Effectiveness of a mini-trampoline training program on balance and functional mobility, gait performance, strength, fear of falling and bone mineral density in older women with osteopenia. Clin Interv Aging. 2019;14:2281-93. doi: $10.2147 /$ CIA.S230008.

7. Padilla C, Molina-Vicenty I, Frontera-Rodríguez M, GarcíaFerré A, Rivera B, Cintrón-Vélez G, et al. Muscle and bone mass loss in the elderly population: Advances in diagnosis and treatment. J Biomed (Syd). 2018;3:40-9. doi: 10.7150/ jbm.23390.

8. Prieto-Peralta M, Sandoval-Cuellar C, Cobo-Mejía EA. Efectos de la actividad física en la calidad de vida relacionada con la salud en adultos con osteopenia y osteoporosis: revisión sistemática y metaanálisis. Fisioterapia. 2017;39(2):8392. doi: 10.1016/j.ft.2016.08.002.

9. Ji MX, Yu Q. Primary osteoporosis in postmenopausal women. Chronic Dis Transl Med. 2015;1(1):9-13. doi: 10.1016/j. cdtm.2015.02.006.

10. Ramírez-Villada J, León-Ariza H, Argüello-Gutiérrez Y, Porras-Ramírez K. Effect of high impact movements on body composition, strength and bone mineral density on women over 60 years. Rev Esp Geriatr Gerontol. 2016;51(2):68-74. doi: 10.1016/j.regg.2015.09.001. 
11. Răduț R, Crăciun A, Silaghi C. Bone markers in arthropathies. Acta Clin Croat. 2019;58(4):716-25. doi: 10.20471/ acc.2019.58.04.19.

12. Weivoda M, Chew C, Monroe D, Farr J, Atkinson E, Geske J, et al. Identification of osteoclast-osteoblast coupling factors in humans reveals links between bone and energy metabolism. Nat Commun. 2020;11(1):87. doi: 10.1038/s41467-01914003-6.

13. Teti A, Econs M. Osteopetroses, emphasizing potential approaches to treatment. Bone. 2017;102:50-9. doi: 10.1016/j.bone.2017.02.002.

14. Vacher J, Bruccoleri M, Pata M. Ostm1 from mouse to human: Insights into osteoclast maturation. Int J Mol Sci. 2020;21(16):5600. doi: 10.3390/ijms21165600.

15. Armamento-Villareal R, Aguirre L, Waters D, Napoli N, Qualls C, Villareal D. Effect of aerobic or resistance exercise, or both, on bone mineral density and bone metabolism in obese older adults while dieting: A randomized controlled trial. J Bone Miner Res. 2020;35(3):430-9. doi: 10.1002/jbmr.3905.

16. Daly R, Gianoudis J, Kersh M, Bailey C, Ebeling P, Krug R, et al. Effects of a 12-month supervised, community-based, multimodal exercise program followed by a 6-month researchto-practice transition on bone mineral density, trabecular microarchitecture, and physical function in older adults: A randomized controlled trial. J Bone Miner Res. 2020;35(3):41929. doi: $10.1002 /$ jbmr.3865.

17. Mohammad R, Smart N, Liang M, Bijeh N, Albanaqi A, Fathi $\mathrm{M}$, et al. The impact of different modes of exercise training on bone mineral density in older postmenopausal women: A systematic review and meta-analysis research. Calcif Tissue Int. 2020;106(6):577-90. doi: 10.1007/s00223-020-00671-w.

18. Kemmler W, Kohl M, Fröhlich M, Jakob F, Engelke K, von Stengel S, et al. Effects of high-intensity resistance training on osteopenia and sarcopenia parameters in older men with osteosarcopenia-one-year results of the randomized controlled franconian osteopenia and sarcopenia trial (FrOST). J Bone Miner Res. 2020;35(9):1634-44. doi: 10.1002/ jbmr.4027.

19. Clark G, Duncan E. The genetics of osteoporosis. Br Med Bull. 2015;113(1):73-81. doi: 10.1093/bmb/ldu042.

20. Turner J. Locus (Genetics). En: Gellman M, Turner J (editores). Encyclopedia of behavioral medicine. New York, NY: Springer. 2013. p. 1170. doi: 10.1007/978-1-4419-10059_708.

21. Zheng HF, Forgetta V, Hsu YH, Estrada K, Rosello-Diez A, Leo PJ, et al. Whole-genome sequencing identifies EN1 as a determinant of bone density and fracture. Nature. 2015;526(7571):112-7. doi: 10.1038/nature14878.

22. Zhang H, Liu L, Ni JJ, Wei XT, Feng GJ, Yang XL, et al. Pleiotropic loci underlying bone mineral density and bone size identified by a bivariate genome-wide association analysis. Osteoporos Int. 2020;31(9):1691-701. doi: 10.1007/ s00198-020-05389-x.
23. Gregson C, Newell F, Leo P, Clark G, Paternoster L, Marshall $\mathrm{M}$, et al. Genome-wide association study of extreme high bone mass: Contribution of common genetic variation to extreme $\mathrm{BMD}$ phenotypes and potential novel BMD-associated genes. Bone. 2018;114:62-71. doi: 10.1016/j.bone.2018.06.001.

24. Warrington N, Kemp J, Tilling K, Tobias J, Evans D. Genetic variants in adult bone mineral density and fracture risk genes are associated with the rate of bone mineral density acquisition in adolescence. Hum Mol Genet. 2015;24(14):4158-66. doi: $10.1093 / \mathrm{hmg} / \mathrm{ddv} 143$.

25. Costantini A, Mäkitie O. Value of rare low bone mass diseases for osteoporosis genetics. Bonekey Rep. 2016;5:773. doi: 10.1038/bonekey.2015.143.

26. Zhang L, Yin X, WangJ, Xu D, Wang Y, YangJ, et al. Associations between VDR gene polymorphisms and osteoporosis risk and bone mineral density in postmenopausal women: A systematic review and meta-analysis. Sci Rep. 2018;8(1):981. doi: 10.1038/s41598-017-18670-7.

27. Mondockova V, Adamkovicova M, Lukacova M, Grosskopf B, Babosova R, Galbavy D, et al. The estrogen receptor 1 gene affects bone mineral density and osteoporosis treatment efficiency in Slovak postmenopausal women. BMC Med Genet. 2018;19(1):174. doi: 10.1186/s12881-018-0684-8.

28. Mitchell J, Cousminer D, Zemel B, Grant S, Chesi A. Genetics of pediatric bone strength. Bonekey Rep. 2016;5:823. doi: 10.1038/bonekey.2016.50.

29. Chen B, Li HZ. Association of IL-6 174G/C (rs1800795) and $572 \mathrm{C} / \mathrm{G}$ (rs1800796) polymorphisms with risk of osteoporosis: A meta-analysis. BMC Musculoskelet Disord. 2020;21(1):330. doi: 10.1186/s12891-020-03334-x.

30. Fu SC, Wang P, Qi MX, Peng JP, Lin XQ, Zhang CY, et al. The associations of TNF- $\alpha$ gene polymorphisms with bone mineral density and risk of osteoporosis: A meta-analysis. Int J Rheum Dis. 2019;22(9):1619-29. doi: 10.1111/1756185X.13647.

31. Sheng X, Cai G, Gong X, Yao Z, Zhu Y. Common variants in OPG confer risk to bone mineral density variation and osteoporosis Fractures. Sci Rep. 2017;7:1739. doi: 10.1038/ s41598-017-01579-6.

32. Chen YC, Zhang L, Li EN, Ding LX, Zhang GA, Hou Y, et al. Association of the insulin-like growth factor-1 single nucleotide polymorphisms rs35767, rs2288377, and rs5742612 with osteoporosis risk: A meta-analysis. Medicine. 2017;96(51):e9231. doi: 10.1097/MD.0000000000009231.

33. Sun J, Zhang $\mathrm{C}$, Xu L, Yang $M$, Yang $\mathrm{H}$. The transforming growth factor- $\beta 1$ (TGF- $\beta 1$ ) gene polymorphisms (TGF$\beta 1$ T869C and TGF- $\beta 1$ T29C) and susceptibility to postmenopausal osteoporosis: a meta-analysis. Medicine. 2015;94(4):e461. doi: 10.1097/MD.0000000000000461.

34. Cannarella R, Barbagallo F, Condorelli R, Aversa A, La Vignera S, Calogero A. Osteoporosis from an endocrine perspective: The role of hormonal changes in the elderly. J Clin Med. 2019;8(10). doi: 10.3390/jcm8101564. 
35. Delitala A, Scuteri A, Doria C. Thyroid hormone diseases and osteoporosis. J Clin Med. 2020;9(4):1034. doi: 10.3390/ jcm9041034.

36. Bloise F, Cordeiro A, Ortiga-Carvalho T. Role of thyroid hormone in skeletal muscle physiology. J Endocrinol. 2018;236(1):R57-R68. doi: 10.1530/JOE-16-0611.

37. Bassett J, Williams G. Role of thyroid hormones in skeletal development and bone maintenance. Endocr Rev. 2016;37(2):135-87. doi: 10.1210/er.2015-1106.

38. Apostu D, Lucaciu O, Oltean-Dan D, Mureșan AD, MoisescuPop C, Maxim A, et al. The influence of thyroid pathology on osteoporosis and fracture risk: A review. Diagnostics (Basel). 2020;10(3):149. doi: 10.3390/diagnostics 10030149.

39. Lindsey R, Mohan S. Skeletal effects of growth hormone and insulin-like growth factor-I therapy. Mol Cell Endocrinol. 2016;432:44-55. doi: 10.1016/j.mce.2015.09.017.

40. Tritos N, Klibanski A. Effects of growth hormone on bone. Prog Mol Biol Transl Sci. 2016;138:193-211. doi: 10.1016/ bs.pmbts.2015.10.008.

41. Tritos N. Focus on growth hormone deficiency and bone in adults. Best Pract Res Clin Endocrinol Metab. 2017;31(1):4957. doi: 10.1016/j.beem.2017.02.002.

42. Blum W, Alherbish A, Alsagheir A, El Awwa A, Kaplan W, Koledova E, et al. The growth hormone-insulin-like growth factor-I axis in the diagnosis and treatment of growth disorders. Endocr Connect. 2018;7(6):R212-R22. doi: 10.1530/ EC-18-0099.

43. YakarS, Werner H, Rosen C. Insulin-like growth factors: actions on the skeleton. J Mol Endocrinol. 2018;61(1):T115-T37. doi: 10.1530/JME-17-0298.

44. Schiffer L, Kempegowda P, Arlt W, O’Reilly M. Mechanisms in endocrinology: The sexually dimorphic role of androgens in human metabolic disease. Eur J Endocrinol. 2017;177(3):R125-R43. doi: 10.1530/EJE-17-0124.

45. Barakat R, Oakley O, Kim H, Jin J, Ko C. Extra-gonadal sites of estrogen biosynthesis and function. BMB Rep. 2016;49(9):488-96. doi: 10.5483/bmbrep.2016.49.9.141.

46. Levasseur R. Fisiología del tejido óseo. EMC - aparato locomotor. 2019;52(2):1-25. doi: 10.1016/S1286935X(19)42130-8.

47. Hendrickx G, Boudin E, van Hul W. A look behind the scenes: The risk and pathogenesis of primary osteoporosis. Nature Rev Rheumatol. 2015;11(8):462-74. 10.1038/nrrheum.2015.

48. Danila R, Livadariu R, Branisteanu D. Calcitonin revisited in 2020. Acta Endocrinol. 2019;15(4):544-8. doi: 10.4183/ aeb.2019.544.

49. Felsenfeld A, Levine B. Calcitonin, the forgotten hormone: Does it deserve to be forgotten? Clin KidneyJ. 2015;8(2):1807. doi: $10.1093 / \mathrm{ckj} / \mathrm{sfv011}$.

50. Martin T, Sims N. Calcitonin physiology, saved by a lysophospholipid. J Bone Miner Res. 2015;30(2):212-5. doi: 10.1002/ jbmr.2449.
51. Silva B, Bilezikian J. Parathyroid hormone: anabolic and catabolic actions on the skeleton. Curr Opin Pharmacol. 2015;22:41-50. doi: 10.1016/j.coph.2015.03.005.

52. Bollerslev J, Pretorius M, Heck A. Parathyroid hormone independent hypercalcemia in adults. Best Pract Res Clin Endocrinol Metab. 2018;32(5):621-38. doi: 10.1016/j. beem.2018.06.005.

53. Goltzman D, Mannstadt M, Marcocci C. Physiology of the calcium-parathyroid hormone-vitamin D Axis. Front Horm Res. 2018;50:1-13. doi: 10.1159/000486060.

54. Gou GH, Tseng FJ, Wang SH, Chen PJ, Shyu JF, Pan RY. Nutritional factors associated with femoral neck bone mineral density in children and adolescents. BMC Musculoskelet Disord. 2019;20(1):520. doi: 10.1186/s12891-019-2901-9.

55. Fabiani R, Naldini G, Chiavarini M. Dietary patterns in relation to low bone mineral density and fracture risk: A systematic review and meta-analysis. Adv Nutr. 2019;10(2):219-36. doi: 10.1093/advances/nmy073.

56. Movassagh E, Vatanparast H. Current evidence on the association of dietary patterns and bone health: A scoping review. Adv Nutr. 2017;8(1):1-16. doi: 10.3945/an.116.013326.

57. Saponaro F, Saba A, Zucchi R. An update on vitamin D metabolism. Int J Mol Sci. 2020;21(18):6573. doi: 10.3390/ ijms21186573.

58. Khammissa R, Fourie J, Motswaledi M, Ballyram R, Lemmer $\mathrm{J}$, Feller L. The biological activities of vitamin $\mathrm{D}$ and its receptor in relation to calcium and bone homeostasis, cancer, immune and cardiovascular systems, skin biology, and oral health. Biomed Res Int. 2018;2018:9276380. doi: 10.1155/2018/9276380.

59. Langsetmo L, Barr S, Dasgupta K, Berger C, Kovacs C, Josse $\mathrm{R}$, et al. Dietary patterns in men and women are simultaneously determinants of altered glucose metabolism and bone metabolism. Nutr Res. 2016;36(4):328-36. doi: 10.1016/j. nutres.2015.12.010.

60. Melaku Y, Gill T, Adams R, Shi Z. Association between dietary patterns and low bone mineral density among adults aged 50 years and above: Findings from the North West Adelaide Health Study (NWAHS). Br J Nutr. 2016;116(8):1437-46. doi: $10.1017 /$ S0007114516003366.

61. Yu P, Ning C, Zhang Y, Tan G, Lin Z, Liu S, et al. Boneinspired spatially specific piezoelectricity induces bone regeneration. Theranostics. 2017;7(13):3387-97. doi: 10.7150/ thno. 19748 .

62. Kammire D, Walkup M, Ambrosius W, Lenchik L, Shapses S, Nicklas BJ, et al. Effect of weight change following intentional weight loss on bone health in older adults with obesity. Obesity. 2019;27(11):1839-45. doi: 10.1002/oby.22604.

63. Proietto J. Obesity and bone. F1000Res. 2020;9:F1000. doi: 10.12688/f1000research.20875.1.

64. Walsh J, Vilaca T. Obesity, type 2 diabetes and bone in adults. Calcif Tissue Int. 2017;100(5):528-35. doi: 10.1007/s00223016-0229-0. 
65. Gkastaris K, Goulis D, Potoupnis M, Anastasilakis A, Kapetanos G. Obesity, osteoporosis and bone metabolism. J Musculoskelet Neuronal Interact. 2020;20(3):372-81.

66. Maghrabi A, Wolski K, Abood B, Licata A, Pothier C, Bhatt D, et al. Two-year outcomes on bone density and fracture incidence in patients with T2DM randomized to bariatric surgery versus intensive medical therapy. Obesity. 2015;23(12):23448. doi: 10.1002/oby.21150.

67. Zhou Y, Chi J, Lv W, Wang Y. Obesity and diabetes as highrisk factors for severe coronavirus disease 2019 (COVID-19). Diabetes Metab Res Rev. 2021;37(2):e3377. doi: 10.1002/ dmrr.3377.

68. Nilsson A, Sundh D, Johansson L, Nilsson M, Mellström D, Rudäng $\mathrm{R}$, et al. Type 2 diabetes mellitus is associated with better bone microarchitecture but lower bone material strength and poorer physical function in elderly women: A population-based study. J Bone Miner Res. 2017;32(5):1062-71. doi: $10.1002 /$ jbmr.3057.

69. Rubin M. Skeletal fragility in diabetes. Ann N Y Acad Sci. 2017;1402(1):18-30. doi: 10.1111/nyas.13463.

70. Furst J, Bandeira L, Fan W, Agarwal S, Nishiyama K, McMahon D, et al. Advanced glycation endproducts and bone material strength in type 2 diabetes. J Clin Endocrinol Metab. 2016;101(6):2502-10. doi: 10.1210/jc.2016-1437.

71. Karim L, Moulton J, Van Vliet M, Velie K, Robbins A, Malekipour F, et al. Bone microarchitecture, biomechanical properties, and advanced glycation end-products in the proximal femur of adults with type 2 diabetes. Bone. 2018;114:329. doi: 10.1016/j.bone.2018.05.030.

72. Hars M, Trombetti A. Body composition assessment in the prediction of osteoporotic fractures. Curr Opin Rheumatol. 2017;29(4):394-401. doi: 10.1097/ BOR.0000000000000406.

73. Rosenberg I. Sarcopenia: origins and clinical relevance. Clin Geriatr Med. 2011;27(3):337-9. doi: 10.1016/j. cger.2011.03.003.

74. Choi K. Sarcopenia and sarcopenic obesity. Korean J Intern Med. 2016;31(6):1054-60. doi: 10.3904/kjim.2016.193.

75. Cruz-Jentoft A, Baeyens J, Bauer J, Boirie Y, Cederholm T, Landi F, et al. Sarcopenia: European Consensus on Definition and Diagnosis: Report of the European working group on sarcopenia in older people. Age Ageing. 2010;39(4):412-23. doi: 10.1093/ageing/afq034.

76. Scicchitano B, Pelosi L, Sica G, Musarò A. The physiopathologic role of oxidative stress in skeletal muscle. Mech Ageing Dev. 2018;170:37-44. doi: 10.1016/j.mad.2017.08.009.

77. Hirschfeld H, Kinsella R, Duque G. Osteosarcopenia: where bone, muscle, and fat collide. Osteoporos Int. 2017;28(10):2781-90. doi: 10.1007/s00198-017-4151-8.

78. Tagliaferri C, Wittrant Y, Davicco M, Walrand S, Coxam V. Muscle and bone, two interconnected tissues. Ageing Res Rev. 2015;21:55-70. doi: 10.1016/j.arr.2015.03.002.
79. Takeuchi $\mathrm{T}$, Soen $\mathrm{S}$, Ishiguro N, Yamanaka $\mathrm{H}$, Tanaka $\mathrm{S}$, Kobayashi M, et al. Predictors of new bone erosion in rheumatoid arthritis patients receiving conventional synthetic disease-modifying antirheumatic drugs: Analysis of data from the drive and desirable studies. Mod Rheumatol. 2021;31(1):34-41. doi: 10.1080/14397595.2019.1703484.

80. Kaji H. Interaction between muscle and bone. J Bone Metab. 2014;21(1):29-40. doi: 10.11005/jbm.2014.21.1.29.

81. Cedeno-Veloz B, López-Dóriga B, Duque G. Osteosarcopenia: Anarrative review. RevEsp Geriatr Gerontol.2019;54(2):1038. doi: 10.1016/j.regg.2018.09.010.

82. Buondonno I, Rovera G, Sassi F, Rigoni M, Lomater C, Parisi $\mathrm{S}$, et al. Vitamin D and immunomodulation in early rheumatoid arthritis: A randomized double-blind placebo-controlled study. PLoS One. 2017;12(6):e0178463. doi: 10.1371/journal.pone.0178463.

83. Ishiguro $\mathrm{N}$, Tanaka $\mathrm{Y}$, Yamanaka $\mathrm{H}$, Yoneda $\mathrm{T}$, Ohira $\mathrm{T}$, Okubo N, et al. Efficacy of denosumab with regard to bone destruction in prognostic subgroups of Japanese rheumatoid arthritis patients from the phase II drive study. Rheumatology. 2019;58(6):997-1005. doi: 10.1093/rheumatology/key416.

84. Schett G, Gravallese E. Bone erosion in rheumatoid arthritis: Mechanisms, diagnosis and treatment. Nat Rev Rheumatol. 2012;8(11):656-64. doi: 10.1038/nrrheum.2012.153.

85. Takeuchi R, Katagiri W, Endo S, Kobayashi T. Exosomes from conditioned media of bone marrow-derived mesenchymal stem cells promote bone regeneration by enhancing angiogenesis. PLoS One. 2019;14(11):e0225472. doi: 10.1371/ journal.pone.0225472.

86. Manor B, Lipsitz L. Physiologic complexity and aging: implications for physical function and rehabilitation. Prog Neuropsychopharmacol Biol Psychiatry. 2013;45:287-93. doi: $10.1016 /$ j.pnpbp.2012.08.020.

87. Tricco A, Thomas S, Veroniki A, Hamid J, Cogo E, Strifler $\mathrm{L}$, et al. Comparisons of interventions for preventing falls in older adults: A systematic review and meta-analysis. JAMA. 2017;318(17):1687-99. doi: 10.1001/jama.2017.15006.

88. Moskalev A, Anisimov V, Aliper A, Artemov A, Asadullah K, Belsky D, et al. A review of the biomedical innovations for healthy longevity. Aging. 2017;9(1):7-25. doi: 10.18632/ aging.101163.

89. Shammas M. Telomeres, lifestyle, cancer, and aging. Curr Opin Clin Nutr Metab Care. 2011; 14(1):28-34. doi: 10.1097/ MCO.0b013e32834121b1.

90. Ferrucci L, González-Freire M, Fabbri E, Simonsick E, Tanaka $\mathrm{T}$, Moore $\mathrm{Z}$, et al. Measuring biological aging in humans: A quest. Aging Cell. 2020;19(2):e13080. doi: 10.1111/ acel.13080.

91. Labbadia J, Morimoto R. The biology of proteostasis in aging and disease. Annu Rev Biochem. 2015;84:435-64. doi: 10.1146/annurev-biochem-060614-033955.

92. Kirkwood T, Kowald A. The free-radical theory of ageingolder, wiser and still alive: Modelling positional effects of 
the primary targets of ROS reveals new support. Bioessays. 2012;34(8):692-700. doi: 10.1002/bies.201200014.

93. Medkour Y, Dakik P, McAuley M, Mohammad K, Mitrofanova D, Titorenko V. Mechanisms underlying the essential role of mitochondrial membrane lipids in yeast chronological aging. Oxid Med Cell Longev. 2017;2017:2916985. doi: $10.1155 / 2017 / 2916985$.

94. Salhotra A, Shah H, Levi B, Longaker M. Mechanisms of bone development and repair. Nat Rev Mol Cell Biol. 2020;21(11):696-711. doi: 10.1038/s41580-020-00279-w.

95. Corrado A, Cici D, Rotondo C, Maruotti N, Cantatore F. Molecular basis of bone aging. IntJ Mol Sci. 2020;21(10):3679. doi: $10.3390 /$ ijms21103679.

96. Ganguly P, El-Jawhari J, Giannoudis P, Burska A, Ponchel F, Jones E. Age-related changes in bone marrow mesenchymal stromal cells: A potential impact on osteoporosis and osteoarthritis development. Cell Transplant. 2017;26(9):1520-9. doi: $10.1177 / 0963689717721201$.

97. Rharass T, Lucas S. Mechanisms in endocrinology: Bone marrow adiposity and bone, a bad romance? Eur J Endocrinol. 2018;179(4):R165-R82. doi: 10.1530/EJE-18-0182.

98. Jilka R, O’Brien C. The role of osteocytes in age-related bone loss. Curr Osteoporos Rep. 2016;14(1):16-25. doi: 10.1007/ s11914-016-0297-0.

99. Qin L, Liu W, Cao H, Xiao G. Molecular mechanosensors in osteocytes. Bone Res. 2020;8:23. doi: 10.1038/s41413-0200099-y.

100. Hong A, Kim S. Effects of resistance exercise on bone health. Endocrinol Metab (Seoul). 2018;33(4):435-44. doi: 10.3803/EnM.2018.33.4.435.

101. Pinheiro M, Oliveira J, Bauman A, Fairhall N, Kwok W, Sherrington C. Evidence on physical activity and osteoporosis prevention for people aged 65+ years: A systematic review to inform the WHO guidelines on physical activity and sedentary behaviour. Int J Behav Nutr Phys Act. 2020;17(1):150. doi: 10.1186/s12966-020-01040-4.

102. Coronado-Zarco R, Olascoaga-Gómez de L, García-Lara A, Quinzaños-Fresnedo J, Nava-Bringas T, Macías-Hernández S. Nonpharmacological interventions for osteoporosis treatment: Systematic review of clinical practice guidelines. Osteoporos Sarcopenia. 2019;5(3):69-77. doi: 10.1016/j. afos.2019.09.005.

103. Allen J, Sun Y, Woods J. Exercise and the regulation of inflammatory responses. Prog Mol Biol Transl Sci. 2015;135:337-54. doi: 10.1016/bs.pmbts.2015.07.003.

104. Faienza M, Lassandro G, Chiarito M, Valente F, Ciaccia L, Giordano P. How physical activity across the lifespan can reduce the impact of bone ageing: A literature review. Int J Environ Res Public Health. 2020;17(6):1862. doi: 10.3390/ ijerph17061862.

105. Tong X, Chen X, Zhang S, Huang M, Shen X, Xu J, et al. The effect of exercise on the prevention of osteoporosis and bone angiogenesis. Biomed Res Int. 2019;8171897. doi: $10.1155 / 2019 / 8171897$.

106. Benedetti M, Furlini G, Zati A, Letizia M. The effectiveness of physical exercise on bone density in osteoporotic patients. Biomed Res Int. 2018:4840531. doi: 10.1155/2018/4840531.

107. Pedersen B, Saltin B. Exercise as medicine - Evidence for prescribing exercise as therapy in 26 different chronic diseases. Scand J Med Sci Sports. 2015;25(3):1-72. doi: 10.1111/ sms.12581.

108. Kemmler W, Shojaa M, Kohl M, von Stengel S. Exercise effects on bone mineral density in older men: A systematic review with special emphasis on study interventions. Osteoporos Int. 2018;29(7):1493-504. doi: 10.1007/s00198-018-4482-0.

109. Gómez-Cabello A, Ara I, González-Agüero A, Casajús J, Vicente-Rodríguez G. Effects of training on bone mass in older adults: A systematic review. Sports Med. 2012;42(4):301-25. doi: 10.2165/11597670-000000000-00000.

110. Mora J, Valencia W. Exercise and older adults. Clin Geriatr Med. 2018;34(1):145-62. doi: 10.1016/j.cger.2017.08.007.

111. Kohrt W, Bloomfield S, Little K, Nelson M, Yingling V, American College of Sports Medicine. American College Of Sports Medicine position stand: Physical activity and bone health. Med Sci Sports Exerc. 2004;36(11). doi: 10.1249/01. mss.0000142662.21767.58.

112. Bull F, Al-Ansari S, Biddle S, Borodulin K, Buman M, Cardon G, et al. World Health Organization 2020 guidelines on physical activity and sedentary behaviour. Br J Sports Med. 2020;54(24):1451-62. doi: 10.1136/bjsports-2020-102955.

113. Vetrovsky T, Steffl M, Stastny P, Tufano J. The efficacy and safety of lower-limb plyometric training in older adults: A systematic review. Sports Med. 2019;49(1):113-31. doi: 10.1007/s40279-018-1018-x.

114. Beavers KM, Beavers DP, Martin SB, Marsh AP, Lyles, MF, Lenchik L, et al. Change in Bone Mineral Density during Weight Loss with Resistance Versus Aerobic Exercise Training in Older Adults. J Gerontol A Biol Sci Med Sci. 2017;72(11):1582-85. doi: 10.1093/gerona/glx048

115. Cornish SM, Myrie SB, Bugera EM, Chase JE, Turczyn D, Pinder M. Omega-3 supplementation with resistance training does not improve body composition or lower biomarkers of inflammation more so than resistance training alone in older men. Nutr Res. 2018;60:87-95. doi:10.1016/j. nutres.2018.09.005

116. Cunha PM, Ribeiro AS, Tomeleri CM, Schoenfeld BJ, Silva AM, Souza MF, et al. The effects of resistance training volume on osteosarcopenic obesity in older women. J Sports Sci. 2018;36(14):1564-71. doi: 10.1080/02640414.2017.1403413

117. Holwerda AM, Overkamp M, Paulussen KJM, Smeets JSJ, Van Kranenburg J, Backx EMP, et al. Protein Supplementation after Exercise and before Sleep Does Not Further Augment Muscle Mass and Strength Gains during Resistance Exercise Training in Active Older Men. J Nutr. 2018;148(11):172332. doi: $10.1093 /$ jn/nxy169 
118. Huovinen V, Ivaska KK, Kiviranta R, Bucci M, Lipponen $\mathrm{H}$, Sandboge $\mathrm{S}$, et al. Bone mineral density is increased after a 16-week resistance training intervention in elderly women with decreased muscle strength. Eur J Endocrinol. 2016;175(6):571-82. doi: 10.1530/EJE-16-0521

119. Mosti MP, Kaehler N, Stunes AK, Hoff J, Syversen U. Maximal strength training in postmenopausal women with osteoporosis or osteopenia. J Strength Cond Res. 2013;27(10):287986. doi: 10.1519/JSC.0b013e318280d4e2

120. Pinto CL, Botelho PB, Carneiro JA, Mota JF. Impact of creatine supplementation in combination with resistance training on lean mass in the elderly. J Cachexia Sarcopenia Muscle. 2016;7(4):413-21. doi: 10.1002/jcsm.12094

121. Shanb A, Youssef E. The impact of adding weight-bearing exercise versus nonweight bearing programs to the medical treatment of elderly patients with osteoporosis. J Family Community Med. 2014;21(3):176-81. doi: 10.4103/22308229.142972

122. Stunes AK, Syversen U, Berntsen S, Paulsen G, Stea TH, Hetlelid KJ, et al. High doses of vitamin $\mathrm{C}$ plus E reduce strength training-induced improvements in areal bone mineral density in elderly men. Eur J Appl Physiol. 2017;117(6):1073-84. doi: 10.1007/s00421-017-3588-y 